\title{
GLOBAL DESIGN OPTIMIZATION OF A REFRIGERATION SYSTEM USING A GENETIC ALGORITHM
}

\author{
L. Govindarajan and T. Karunanithi \\ Department of Chemical Engineering \\ Faculty of Engineering and Technology \\ Annamalai University, India \\ cdl1ln@sancharnet.in
}

\begin{abstract}
The optimal design of industrial three-stage refrigeration systems to minimize total production cost has been effectively implemented using an genetic algorithm (GA), which is an efficient alternative for conventional search algorithms. In this article the global optimum design parameters of a refrigeration system obtained by using GA is compared with the Nelder-Mead simplex search algorithm. The results prove that global design optimization using GA is more robust and simple, as it requires no initial guess values of design variables. Hence the proposed technique is well suited for designing a variety of industrially important systems.
\end{abstract}

\section{OPSOMMING}

Die optimum ontwerp van 'n driestadium-vriessisteem om totale produksiekoste te beperk, word doeltreffend met behulp van 'n genetiese algoritme (GA) as alternatief vir konvensionele soekalgoritmes in werking gestel. Die navorsing is daarop toegespits om die globale optimum ontwerpparameters van die GA met die Nelder-Mead Simpleks-soekalgoritme te vergelyk. Die resultate toon dat die GA se globale optimum ontwerp robuust en eenvoudig is aangesien geskatte aanvangswaardes vir ontwerpveranderlikes nie benodig word nie. Derhalwe is die GA-tegniek besonder geskik vir die ontwerp van nywerheidsisteme van uiteenlopende aard. 


\section{INTRODUCTION}

Refrigeration finds extensive application in lubricating-oil purification, low-temperature reactions, and separation of volatile hydrocarbons in petroleum industries. It is also used in the manufacture of ice and the dehydration of gases in many process industries and in the air conditioning of buildings. Refrigeration plays a vital role in the treatment, transportation, and preservation of food, beverages, etc. Process refrigeration is used at many different temperature levels to condense or cool gases, vapors and liquids.

The optimal design of industrial processes and equipment was carried out with the conventional mathematical programming techniques that use algorithms devised for solving general optimization problems (Knopf [1], Grossmann [2]). These algorithms are only effective for moderately constrained optimization problems with continuous decision variables, whereas the industrial process and equipment design problems contain discrete, as well as continuous, variables and involve a large number of constraints. A heuristic method was also reported for the design of industrial equipment but this method may end in local optimum values due to its greedy nature. It is not a general method due to the fact that special heuristic rules may be needed for solving the specific industrial design problems (Modi [3], Yeh [4]). Hence, these methods require laborious and time-consuming computation steps to arrive at optimum values in the design of industrial processes and equipment.

The optimum design of the industrial refrigeration system is characterized by the presence of non-convex design spaces. The standard linear, simplex search algorithm and descent techniques were applied to the design of a refrigeration system. The commonly used simplex search method is the Nelder-Mead search algorithm, as it is suitable for problems that are very nonlinear and/or have a number of discontinuities. Generally, these methods are inefficient, computationally expensive, and in most cases, find a local optimum that is closest to the initial guess values.

Recently, a global optimization technique known as the genetic algorithm (GA) has become a candidate for many optimization applications due to its flexibility and efficiency (Goldberg [5]). GA is a stochastic searching algorithm that combines artificial survival of the fittest with genetic operators abstracted from nature to form a surprisingly robust mechanism that is suitable for a variety of optimization problems. GA hops randomly from point to point, thus allowing it to escape from local optimums in which the other algorithm might land. Therefore, the GA-based global optimum problem can be approached with high probability. This article describes the design of a three-stage industrial refrigeration system using the genetic algorithm and considering the various process constraints to minimize the total cost involved in the operation.

\section{THE GENETIC ALGORITHM IN OPTIMAL DESIGN OF INDUSTRIAL EQUIPMENT}

The genetic algorithm is a computer-based search-and-optimization technique based on the mechanics of natural genetics and selection. The optimization problem using GA consists of the following steps: 
1. Coding and decoding of problem variables.

2. Formulation of the fitness function.

3. Genetic operations.

The genetic algorithm finds extensive application in a variety of problems in industry. GA is used in large-scale industrial energy integration ( $\mathrm{Yu}$ [6]), optimal design of multiproduct batch chemical processes (Wang [7], Haro [8]), optimization of chemical flow shop sequencing (Cartwright [9]), sequencing of batch operations for a highly coupled production process (Lohl [10]), optimization of operations in an industrial cogeneration system (Manolas [11]), and design batch semicontinuous process plant treating multiple products.

\section{PROBLEM FORMULATION}

\section{Optimization of Industrial Refrigeration System}

The refrigeration system shown in Figure 1 has three stages in which a hot stream is cooled by using liquid refrigerant. Each stage consists of a heat exchanger with hot stream on one side of the heat exchange surface and a boiling refrigerant on the other side.

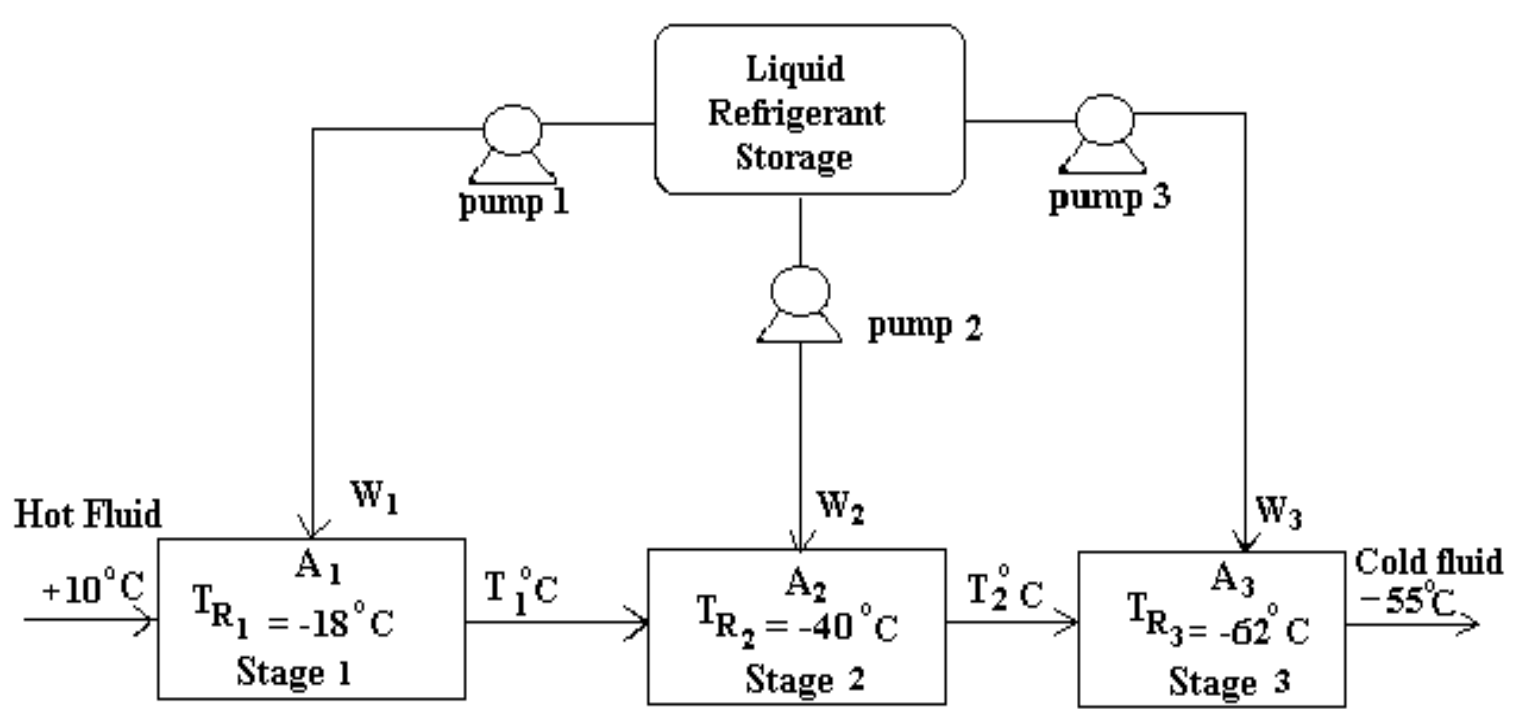

Figure 1. Three Stage Refrigeration System

The temperatures at which the refrigerants boil are known at each stage and hence the rate of heat transfer is determined by the area of the heat exchange surface, at a given flow rate and inlet temperature of the hot fluid. The optimal design problem necessitates the determination of the surface area of three heat exchangers required to cool a fluid with a specific heat of $4186.8 \mathrm{~J} / \mathrm{kg}^{\circ} \mathrm{C}$ flowing at a rate of $10,800 \mathrm{~kg}$ per hour from $10^{\circ} \mathrm{C}$ to $-55^{\circ} \mathrm{C}$. The unit is expected to operate for a minimum of 300 days in a year. The system parameters used in the design are the latent heat of the refrigerant $(\lambda), 2,32,600 \mathrm{~J} / \mathrm{Kg}$, and the overall heat transfer coefficient in stages, $1130 \mathrm{~J} / \mathrm{s} \mathrm{m}^{2}{ }^{\circ} \mathrm{C}$. 
The design objective is to minimize the total cost for the three stages in the refrigeration system given by

$$
\mathrm{C}=\sum_{\mathrm{i}=1}^{3}\left[\mathrm{a}_{\mathrm{i}}\left(\mathrm{A}_{\mathrm{i}}\right)^{0.5}+\mathrm{b}_{\mathrm{i}} \mathrm{W}_{\mathrm{i}}\right]
$$

The first term represents the capital cost related to the area of heat exchange surface and the second term is the operating cost of supplying the refrigerant. The purpose of optimization is to obtain reasonable values of design variables i.e. temperatures of fluid leaving the stages 1 and 2. The area of heat exchange and the liquid refrigerant addition rate in each stage are determined by using the design variables. The liquid refrigerant temperature in each stage is

$$
\mathrm{T}_{1}=-18^{\circ} \mathrm{C} ; \quad \mathrm{T}_{2}=-40^{\circ} \mathrm{C} ; \quad \mathrm{T}_{3}=-62^{\circ} \mathrm{C} ;
$$

The temperature at which the fluid enters the system $\left(\mathrm{T}_{0}\right)$ is $10^{\circ} \mathrm{C}$ and the temperature at which it leaves the system $\left(\mathrm{T}_{3}\right)$ is $-55^{\circ} \mathrm{C}$. The temperature leaving the given stage must be greater than the refrigerant temperature. Therefore, the constraints on the design variables are

$$
\begin{aligned}
& \mathrm{T}_{0}=10^{\circ} \mathrm{C} \geq \mathrm{T}_{1} \geq-18^{\circ} \mathrm{C} \\
& \mathrm{T}_{1} \geq \mathrm{T}_{2} \geq-40^{\circ} \mathrm{C}
\end{aligned}
$$

The heat transfer rate at stage $\mathrm{i}$ :

$$
\mathrm{Q}_{\mathrm{i}}=\mathrm{U}_{\mathrm{i}} \times \mathrm{A}_{\mathrm{i}} \times\left(\Delta \mathrm{T}_{\mathrm{i}}\right)_{\ln }
$$

The log mean temperature at stage $\mathrm{i}$ :

$$
\left(\Delta \mathrm{T}_{\mathrm{i}}\right)_{\ln }=\frac{\left(\mathrm{T}_{\mathrm{i}-1}-\mathrm{T}_{\mathrm{i}}\right)}{\ln \frac{\left(\mathrm{T}_{\mathrm{i}-1}-\mathrm{T}_{\mathrm{R}_{\mathrm{i}}}\right)}{\left(\mathrm{T}_{\mathrm{i}}-\mathrm{T}_{\mathrm{R}_{\mathrm{i}}}\right)}}
$$

The energy balance over refrigerant indicates

$$
\mathrm{Q}_{\mathrm{i}}=\lambda_{\mathrm{i}} \times \mathrm{W}_{\mathrm{i}}
$$

The energy balance over the fluid indicates

$$
\mathrm{Q}_{\mathrm{i}}=\mathrm{F} \times \mathrm{Cp} \times\left(\mathrm{T}_{\mathrm{i}-1}-\mathrm{T}_{\mathrm{i}}\right)
$$

\section{GA Solution Methodology}

\section{Coding}

In the genetic algorithm, the design variables are first coded in string structures. Binary coded strings having 0 and 1 are widely used. The desired solution accuracy determines the length of the string. A point in the search space is represented by an eight-bit string and is allocated according to a linear mapping rule: 


$$
X_{j}=X_{j}^{\min }+\frac{X_{j}^{\max }-X_{j}^{\min }}{\left(2^{L_{j}}-1\right)} \times D_{k}
$$

The operation of GA begins with a population of random strings representing the design variable. Each string is evaluated to find the fitness function. The three main GA operators reproduction, crossover and mutation, are applied to the random population to create a new population. The population is evaluated and tested until the termination criterion is met, iteratively altered by the GA operators. Generation in GA represents the cycle of operation by the genetic operators and the evaluation of the fitness function.

\section{Reproduction}

Reproduction selects good strings in a population and forms a mating pool. The reproduction operator will pick the above-average strings from the current population. Their copies are then inserted into the mating pool in a probabilistic manner. The string with a higher fitness value will represent a larger range in the cumulative probability values and therefore has a higher probability of being copied into the mating pool. On the other hand, a string with a smaller fitness value represents a smaller range in the cumulative probability values and has a smaller probability of being copied into the mating pool.

\section{Crossover}

In the crossover operation, exchanging information between strings of the mating pool creates new strings. The two strings participating in the crossover operation are known as parent strings and the resulting strings are known as child strings. The child strings produced may be good or not, which depends on the performance of the crossover site. The effect of crossover may be beneficial or detrimental. In order to preserve some good strings that are already present in the mating pool, not all strings in the mating pool are used in the crossover.

\section{Mutation}

Mutation is needed to create a point in the neighborhood of the current point, thereby achieving local search around the current solution. The mutation is also used to maintain diversity in the population.

\section{Formulation of the Fitness Function}

The objective is to minimize the total cost, subject to various constraints governing the process. A penalty function approach is used to handle the explicit constraints. Penalty terms are incorporated in the fitness function and are said to reduce the fitness of the string according to the magnitude of their violation.

$$
\operatorname{Min} \psi=\sum_{\mathrm{i}=1}^{3}\left[\mathrm{a}_{\mathrm{i}}\left(\mathrm{A}_{\mathrm{i}}\right)^{0.5}+\mathrm{b}_{\mathrm{i}} \mathrm{W}_{\mathrm{i}}\right]+\lambda\left[\sum_{\mathrm{z} \in \mathrm{LVC}}^{\mathrm{N}}\left|\mathrm{C}_{\mathrm{z}}-\mathrm{C}_{\mathrm{z} \text { (limit) }}\right|\right]
$$

The fitness is obtained by transforming the minimization problem into a maximization problem as 


$$
\mathrm{FIT}=\frac{1}{1+\psi}
$$

\section{RESULTS AND DISCUSSION}

The proposed GA-based optimization has been successfully incorporated for the optimal design of a three-stage refrigeration system. The cost coefficients of three-stage the refrigeration system are given in Table 1.

\begin{tabular}{|l|c|c|c|}
\hline \multirow{2}{*}{ Cost Coefficients } & \multicolumn{3}{|c|}{ Stages } \\
\cline { 2 - 4 } & 1 & 2 & 3 \\
\hline Capital cost parameters (a), cost units $/ \mathrm{s}\left(\mathrm{m}^{2}\right)^{1 / 2}$ & 0.00911 & 0.00911 & 0.0273 \\
\hline Operating cost parameters (b), cost units $/ \mathrm{Kg}$ & 0.053 & 0.08 & 0.1066 \\
\hline
\end{tabular}

Table 1. Cost Coefficients for an Industrial Three-Stage Refrigeration System

The design problem has been implemented using the Nelder-Mead Simplex search algorithm with the MATLAB optimization toolbox. The variation of the total cost for various initial guesses of design variables has been studied and the results are given in Table 2.

\begin{tabular}{|c|c|c|c|c|}
\hline \multicolumn{2}{|c|}{ Initial Guess of Design Parameters } & \multicolumn{2}{|c|}{ Optimized Design Values } & \multirow{2}{*}{$\begin{array}{c}\text { Total Cost } \\
\text { Cost Units/Year }\end{array}$} \\
\hline $\mathrm{T}_{1}{ }^{\circ} \mathrm{C}$ & $\mathrm{T}_{2}{ }^{\circ} \mathrm{C}$ & $\mathrm{T}_{1}{ }^{\circ} \mathrm{C}$ & $\mathrm{T}_{2}{ }^{\circ} \mathrm{C}$ & \\
\hline Less than -1 & Less than -3 & \multicolumn{2}{|c|}{ Solutions diverge } & - \\
\hline-1 & -3 & -1.57 & -3.20 & 13370967 \\
\hline-2.0 & -7 & -2.13 & -11.00 & 13217164 \\
\hline-3.0 & -11 & -3.20 & -17.29 & 13012384 \\
\hline-4.0 & -15 & -4.26 & -23.58 & 12791568 \\
\hline-5.0 & -19 & -5.33 & -29.87 & 12571384 \\
\hline-6.0 & -23 & -6.39 & -36.15 & 12414942 \\
\hline-7.0 & -27 & -7.92 & -34.93 & 12419525 \\
\hline-8.0 & -31 & -8.10 & -36.81 & 12406587 \\
\hline-9.0 & -35 & -9.39 & -36.31 & 12402392 \\
\hline-9.5 & -37 & -9.83 & -36.30 & 12402294 \\
\hline Above -9.5 & Above -37 & \multicolumn{2}{|c|}{ Solutions diverge } & - \\
\hline
\end{tabular}

Table 2: Influence of Initial Guess Values on Optimal Design Parameter using the Nelder-Mead Simplex Search Method

It can be concluded that this type of implementation requires a good starting point. However, in continuous process operations, it is not possible to predict a suitable starting point to obtain the optimum design. Conventional search methods such as the Nelder-Mead simplex search algorithm arrive at the local optimum values nearer to the initial guess of design variables. 
The proposed method of GA-based optimal design overcomes the shortcomings of the conventional search method as it starts with a population representing many points. The results of the proposed method have been compared with the Nelder-Mead Simplex search algorithm and are given in Table 3.

\begin{tabular}{|c|c|c|c|c|c|c|c|}
\hline \multirow{2}{*}{ Optimization Method } & \multicolumn{5}{|c|}{ Design Parameters } & $\begin{array}{c}\text { Total Cost } \\
\text { Cost Units/Year }\end{array}$ \\
\cline { 2 - 7 } & $\begin{array}{c}\mathrm{A}_{1} \\
\mathrm{~m}^{2}\end{array}$ & $\begin{array}{c}\mathrm{A}_{2} \\
\mathrm{~m}^{2}\end{array}$ & $\begin{array}{c}\mathrm{A}_{3} \\
\mathrm{~m}^{2}\end{array}$ & $\begin{array}{c}\mathrm{W}_{1} \\
\mathrm{Kg} / \mathrm{hr}\end{array}$ & $\begin{array}{c}\mathrm{W}_{2} \\
\mathrm{Kg} / \mathrm{hr}\end{array}$ & $\begin{array}{c}\mathrm{W}_{3} \\
\mathrm{Kg} / \mathrm{hr}\end{array}$ & \\
\hline $\begin{array}{c}\text { Nelder-Mead } \\
\text { Simplex Search }\end{array}$ & 13.67 & 23.34 & 14.45 & 3852 & 5148 & 3632 & $124,02,294$ \\
\hline $\begin{array}{c}\text { Genetic } \\
\text { Algorithm }\end{array}$ & 13.44 & 23.56 & 14.43 & 3816 & 5184 & 3625 & $124,02,243$ \\
\hline
\end{tabular}

Table 3: Comparison between the Nelder-Mead Simplex Search Method and Genetic Algorithm-based Optimization Technique

The results indicate that the design values obtained from GA show improvement in the minimization of the total cost over those obtained by the considered conventional simplex algorithm and the same results are expected to be obtained by applying any other conventional mathematical techniques. The proposed GA-based design optimization can be successfully implemented for the design of industrial three-stage refrigeration process systems, due to the following advantages:

1. GA has the ability to give solutions near enough to global optimal values.

2. GA is efficient in handling problems having discrete variables and non-convex behaviour, which are common characteristics encountered in the design of industrial equipments.

3. Initial guesses of the optimization variables are not required for GA, whereas the Nelder-Mead-like simplex algorithm initial estimate and descent direction are very important for obtaining feasible solutions.

4. GA, due to its intelligent approach, results in faster convergence when compared to the conventional mathematical, heuristics and other artificial intelligence techniques such as simulated annealing.

5. GA is simple in structure and convenient for implementation in the design of largescale industrial equipment.

\section{CONCLUSION}

The optimal design of industrial equipment such as a three-stage refrigeration system has been successfully implemented using the genetic algorithm. The genetic algorithm offers significant advantages over the conventional mathematical programming methods and heuristic optimization techniques as it provides global design parameters and is effective in handling problems with discrete variables having a large number of constraints. The genetic algorithm can be used as a universal technique for solving a variety of industrial design problems. 


\section{Notation}

$\begin{array}{ll}\text { a } & \text { Capital cost coefficient, cost units } / \mathrm{s}\left(\mathrm{m}^{2}\right)^{0.5} \\ \text { A } & \text { Area of heat exchange surface, } \mathrm{m}^{2} \\ \text { b } & \text { Operating cost coefficient, cost units } / \mathrm{Kg} \\ \text { Cp } & \text { Specific heat of fluid, } \mathrm{J} / \mathrm{kg}{ }^{\circ} \mathrm{C} \\ \text { C } & \text { Total cost, cost units } / \text { year } \\ \text { D } & \text { Equivalent decimal value } \\ \text { F } & \text { Hot fluid flow rate, } \mathrm{Kg} / \mathrm{hr} \\ \text { FIT } & \text { Fitness function } \\ \text { GA } & \text { Genetic algorithm } \\ \text { LVC } & \text { Limit violated constraint } \\ \text { Q } & \text { Rate of heat transfer, } \mathrm{J} / \mathrm{s} \\ \text { T } & \text { Temperature, }{ }^{\circ} \mathrm{C} \\ \mathrm{U} & \text { Overall heat transfer coefficient, } \mathrm{J} / \mathrm{s} \mathrm{m}{ }^{2}{ }^{\circ} \mathrm{C} \\ \text { W } & \text { Liquid refrigerant addition rate, } \mathrm{Kg} / \mathrm{hr} \\ \text { X } & \text { Design variable }\end{array}$

\section{Subscripts}

$\begin{array}{ll}\mathrm{i} & \text { Stages } \\ \mathrm{j} & \text { Design variable } \\ \mathrm{k} & \text { Sub-string } \\ \mathrm{R} & \text { Refrigerant }\end{array}$

\section{Superscripts}

L Number of binary bits in a sub-string

limit Constraint limit

min, max Limits of the design variables

z Constraint function Portia Matseke $\{$ WITS

\section{Special Symbols}
$\lambda$
Penalty factor
$\lambda_{\mathrm{i}}$
Latent heat of refrigeration, $\mathrm{J} / \mathrm{Kg}$
$\psi$
Objective function to be minimized

\section{REFERENCES}

[1] Knopf F.C, Okos M.R \& Reklaitis G.V, (1982), Optimal Design of Batch/SemiContinuous Processes, Industrial Engineering Chemistry Process Design and Development, Vol 21, p 79-86.

[2] Grossmann I., \& Sargent R.W.H, (1979), Optimum Design of Multipurpose Chemical Plants, Industrial Engineering Chemistry Process Design and Development, Vol 18, p 343-348,

[3] Modi A.K \&Karimi A, (1989), Design of multiproduct batch processes with finite intermediate storage, Computers and Chemical Engineering, Vol 13, p127-136. 
[4] Yeh N.C \& Reklaitis. G.V, (1987) Synthesis and sizing of batch/ semi continuous process: Single product plants, Computers and Chemical Engineering, Vol 11, p 639645.

[5] Goldberg D.E., 1989. Genetic Algorithms in Search, Optimization and Machine Learning, Addison - Wesley, New York.

[6] Yu H, Fang H, Yao P \& Yuan Y, A combined genetic algorithm/simulated annealing algorithm for large scale system energy integration, Computers and Chemical Engineering, Vol 24, p 2023-2035, 2000.

[7] Wang C, Quan H \& Xu X, Optimal design of multi product batch chemical process using genetic algorithms, Industrial Engineering Chemistry Research, Vol 35, p 3560$3566,1996$.

[8] Haro L.B, Pantel C.A, Domenech S \& Pibouleau L, Design of multipurpose batch chemical plants using a genetic algorithm, Computers and Chemical Engineering, Vol 22, S777-S780, 1998.

[9] Cartwright H.M \& Long R.A, Simultaneous optimization of chemical flow shop sequencing and topology using genetic algorithm, Industrial Engineering Chemistry Research, 32, 2706-2713,1993.

[10] Lohl T, Sculz, C Engell S, Sequencing of batch operations for a highly coupled production process: genetic algorithms versus mathematical programming, Computers and Chemical Engineering, 22, S579-S585, 1998.

[11] Manolas D.A, Gialamass T.P, Frangopoulos C.A \& Tsahalis D.T, A genetic algorithm for operation optimization of an industrial cogeneration system, Computers and Chemical Engineering, 20, S1107-S1112, 1996. 
